\title{
International Journal of Communications and Networks (DOI:10.28933/IJCN)
}

\section{The influence of the media in the construction of food habits in children}

\author{
Barros, M.I.T1; Sousa, A.A2; Pontes, M.M.L3
}

1Estudante do Curso de Bacharelado em Nutrição da FSM; 2Estudante do Curso de Bacharelado em Nutrição da FSM; 3Docente do Curso de Bacharelado em Nutrição da FSM;

\section{ABSTRACT}

Introduction: Since the media is one of the main instruments of communication today, having a strong capacity to influence the construction of eating habits, especially in the children's audience, we find pertinence in the association of these factors associated to the family nucleus. With regard to the family context, it is seen that children become more vulnerable to this technology because they spend a large part of their day surrounded by various instruments that, in most cases, allow negative access when it comes to conceptions food products, which is a consequence of the constant association of food advertisements with low nutritional content. With regard to the family context, it is seen that children become more vulnerable to this technology because they spend a large part of their day surrounded by various instruments that, in most cases, allow negative access when it comes to unhealthy conceptions food products, which is a consequence of the constant association of food advertisements with low nutritional content. Objective: Therefore, this work aims to correlate the influence of the media in the construction of eating habits in children. Methodology: This is a review study of the literature, with papers in Portuguese, researched in the period from 2011 to 2017 referenced in the Google Scholar database, having the following expressions as descriptors: Influence of Media and Eating Habits. Results and Discussion: We noticed that most publications we found claims that the media has a strong relationship in the construction of children's eating habits since they are more susceptible to influence and manipulation, because they do not have a critical sense formed yet. Another relevant aspect is the interference of food in the family nucleus, which generates resistance to the adhesion of new healthy eating habits. Thus, we consider the importance of discussions involving media power in the formation of eating habits in childhood, which could be a contributing factor in promoting health and preventing possible disorders related to food choices. Conclusion: That said, public policies become alternatives to beings that are considered as an intervention tool, and an evaluation and monitoring of contents that enhance inappropriate food practices, which are disseminated and directed at the child-juvenile audience by the media.

\section{Keywords:}

Food Behavior; Health education; Child Nutrition.

*Correspondence to Author:

Barros, M.I.T

Estudante do Curso de Bacharelado em Nutrição da FSM

How to cite this article:

Barros, M.I.T; Sousa, A.A; Pontes, M.M.L. The influence of the media in the construction of food habits in children. International Journal of Communications and Networks, $2018,1: 5$

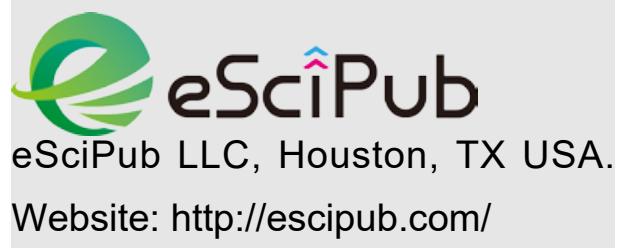

